\title{
Graph representation of geological stratum
}

\author{
Przemysław Lisowski
}

AGH University of Science and Technology, Faculty of Geology, Geophysics and Environmental Protection, Department of Geoinformatics and Applied Computer Science; al. A. Mickiewicza 30, 30-059 Krakow, Poland; e-mail: plis@agh.edu.pl

(c) 2016 Authors. This is an open access publication, which can be used, distributed and reproduced in any medium according to the Creative Commons CC-BY 4.0 License requiring that the original work has been properly cited.

Geology, geophysics and environmental protection sciences provide large amounts of data. These data can be stored in various structures. Most of them are stored in files. It is possible to store these data in databases. One example of databases for earth sciences is a Geokarpat database (Kotlarczyk et al. 1997). This database was developed over many years (Piórkowski \& Gajda 2009). Other geological databases are, for example, database MIDAS (MIDAS 2015) and central database of the geological data (CBDG 2015). Solutions listed above are based on the relational data model. This model is not perfect for data analysis, as there are a lot of complicated relationships between the entities (Dominguez-Sal et al. 2010). A typical use of SQL in this case requires the creation of multiple joins and a large amount of calculations.

Graph data model is gaining popularity because it allows representation similar to the natural network model of relationships between data (Horzyk 2013). Applications of this model within the earth sciences are extensive, including solutions for GIS systems. One of example graph application is the creation of a virtual generator of the city using database Neo4j (Płuciennik \& Płuciennik-Psota 2014). Graph structure reproduces biological structure of memory well (Horzyk 2013). Based on this advantage, there are new opportunities to store and analyze geological data. The use of graphs to record those data enables data analyses in similar manner like in associative neural networks (Horzyk 2013).

Geological stratum often has a complex structure, for example: around area of tectonic faults (often multiple faults in history), intrusive rocks in stratum. Possibilities of using graph databases for storing geological data were checked. This study focuses on proposing a graph representation of geological stratum. The proposed graph structure was implemented in the graph database. Presentation of the history of geological stratum in relational databases is difficult. Studies show an example of stratum graph model, which enables data mining of stratum history in easy method, because graph database systems are designed to make search queries to find similarity in data. Additionally, the results of this study demonstrated useful query. Moreover, software and possible methods of construction of graph models were studied. As shown by the results, an analysis of complex models of geological stratum can be less complicated. Research shows that finding dependences in the graph representation of the geological layers can be beneficial in geological analyses.

\section{REFERENCES}

CBDG, 2015. http://baza.pgi.gov.pl/ [access: 15 February 2016].

Dominguez-Sal D., Urbón-Bayes P., Giménez-Vañó A., Gómez-Villamor S., Martínez-Bazán N. \& Lluís Larriba-Pey J., 2010. Survey of Graph Database Performance on the HPC Scalable Graph Analysis Benchmark. [in:] Shen H.T., Pei J., Özsu M.T., Zou L., Lu J., Ling T.-W., Yu G., Zhuang Y. \& Shao J., Web-Age Information Management, Springer, Berlin, Heidelberg, 37-48.

Horzyk A., 2013. Sztuczne systemy skojarzeniowe i asocjacyjna sztuczna inteligencja. Akademicka Oficyna Wydawnicza Exit, Warszawa.

Kotlarczyk J., Krawczyk A., Leśniak T. \& Słomka T., 1997. Geologiczna baza danych GeoKarpaty dla polskich Karpat fliszowych. Wydawnictwo własne WGGiOŚ AGH, Kraków. 
MIDAS, 2015. http://geoportal.pgi.gov.pl/portal/page/portal/ MIDASGIS [access: 15 February 2016].

Piórkowski A. \& Gajda W., 2009. A construction of multidimensional geological database. Studia Informatica, 30, 2B, 179-190.
Płuciennik T. \& Płuciennik-Psota E., 2014. Using Graph Database in Spatial Data Generation. [in:] Man-Machine Interactions 3, Springer International Publishing, Berlin, 643-650. 